\title{
Polylactide/Halloysite Nanocomposite Foams: Particle Dispersion and Mechanical Strength
}

\author{
M. ERYILDIZ* AND M. Altan \\ Yildiz Technical University, Department of Mechanical Engineering, 34349 Istanbul, Turkey
}

\begin{abstract}
Polylactide (PLA) foams have been used in biomedical applications such as scaffolding and tissue engineering due to its biocompatibility. However, its brittleness and low melt strength limit it wide range of applications. In this study, halloysite nanotube (HNT) was used in order to improve the properties of the PLA foams. PLA/HNT composites were compounded on twin screw extruder within constant concentration of HNT (0.5 wt\%). In extruder processing, compounding was realized in two different ways. In the first one, PLA/HNT was melt-mixed by the addition of $1 \mathrm{wt} \%$ azodicarbonamide $(\mathrm{AC})$ in order to enhance the dispersion of the nanoparticles in the matrix. In the second one, azodicarbonamide was not added into the extruder during compounding of PLA/HNT. After melt-mixing process, neat PLA and PLA/HNT pellets were subject to chemical foaming on a conventional injection molding machine and tensile test samples were obtained. Mechanical test and morphological investigations were made in order to observe the tensile properties and foam cell generation of PLA composites. It has been seen that HNT addition in $0.5 \mathrm{wt} \%$ increased the tensile strength and elongation of PLA/HNT about $50 \%$ and $70 \%$, respectively. Morphological results showed that HNT could improve the cell formation of PLA foams by decreasing the cell pore size and cell density. The usage of AC in melt-mixing stage of the polymer composite induced a slight increment in the tensile properties of the material due to the dispersant and plasticizer effect of azodicarbonamide.
\end{abstract}

DOI: 10.12693/APhysPolA.135.619

PACS/topics: poly(lactic acid), foaming, injection molding, chemical foaming agent, halloysite

\section{Introduction}

PLA is a biobased, biodegradable, and biocompatible aliphatic polyester that make the polymer usable in different fields of application from food packages to biomedical applications. Besides, PLA foams have been used in tissue engineering due its ability of mimicking human bone scaffold such as cancellous bone [1]. However, PLA exhibits poor foamability because it suffers from low melt strength and elasticity, slow crystallization, and narrow processing window $[2-5]$. Besides, it is very difficult to control the foaming of PLA by injection molding because of its low melt strength and slow crystallization kinetics $[4,6-8]$. Usage of inorganic or natural fillers is one of the effective ways to improve performance of PLA and its foaming ability. HNT is a kind of inorganic filler that has received considerable attention lately due to its environmental friendliness, biocompatibility, and natural abundance, which make it an important nanomaterial for biomedical applications [9]. There have been several studies related to PLA composites foams [6-10]. However, investigations about PLA composite foams are still continuing and researches on PLA/HNT foams are rare. In this study, halloysite nanotube (HNT) reinforced PLA foams were prepared by melt-mixing method in two alternative ways and the effects of HNT on the tensile properties and foam cell generation of PLA foams were observed.

*corresponding author; e-mail: mdemirci@yildiz.edu.tr

\section{Experimental procedure}

Commercial poly(lactic acid) (PLA 3001D, Natureworks supplied by Resinex Inc., Turkey) was used in the experiments. The foaming agent was azodicarbonamide (Sigma-Aldrich). Halloysite particles were supplied by ESAN (Eczacibasi Inc., Turkey) with a wall thickness of 7-8 $\mathrm{nm}$. Before compounding, the PLA and HNT were dried at $80^{\circ} \mathrm{C}$ in a vacuum oven for $24 \mathrm{~h}$. PLA/HNT composites were compounded on a twin screw extruder (Rondol, England, $L / D=10$ ) within constant concentration of HNT (0.5 wt\%). In extruder processing, compounding was realized in two different ways. In the first way, PLA and HNT was melt mixed by the addition of $1 \mathrm{wt} \%$ azodicarbonamide (AC) (PLA/HNT/AC) in order to enhance the dispersion of the nanoparticles by AC. It has been known that foaming agents decrease the viscosity of the polymers and behave like a plasticizer. In the second way, azodicarbonamide was not added into the extruder during the compounding of PLA/HNT. After melt-mixing, neat PLA, PLA/HNT and PLA/HNT/AC pellets were injection molded with chemical foaming agent in order to obtain PLA foams for tensile test. The cell morphology of foamed samples were observed on scanning electron microscope (SEM, EVO LS10). The tensile properties of nanocomposite foams were measured with a universal tensile test machine (Instron 5982) with $1 \mathrm{~mm} / \mathrm{min}$ of test speed. The reported data were the average of three tests.

\section{Results and discussion}

SEM micrographs of the fracture surfaces of the PLA foams are given in Fig. 1. The SEM micrographs reveal that larger porosities were generated in neat PLA 


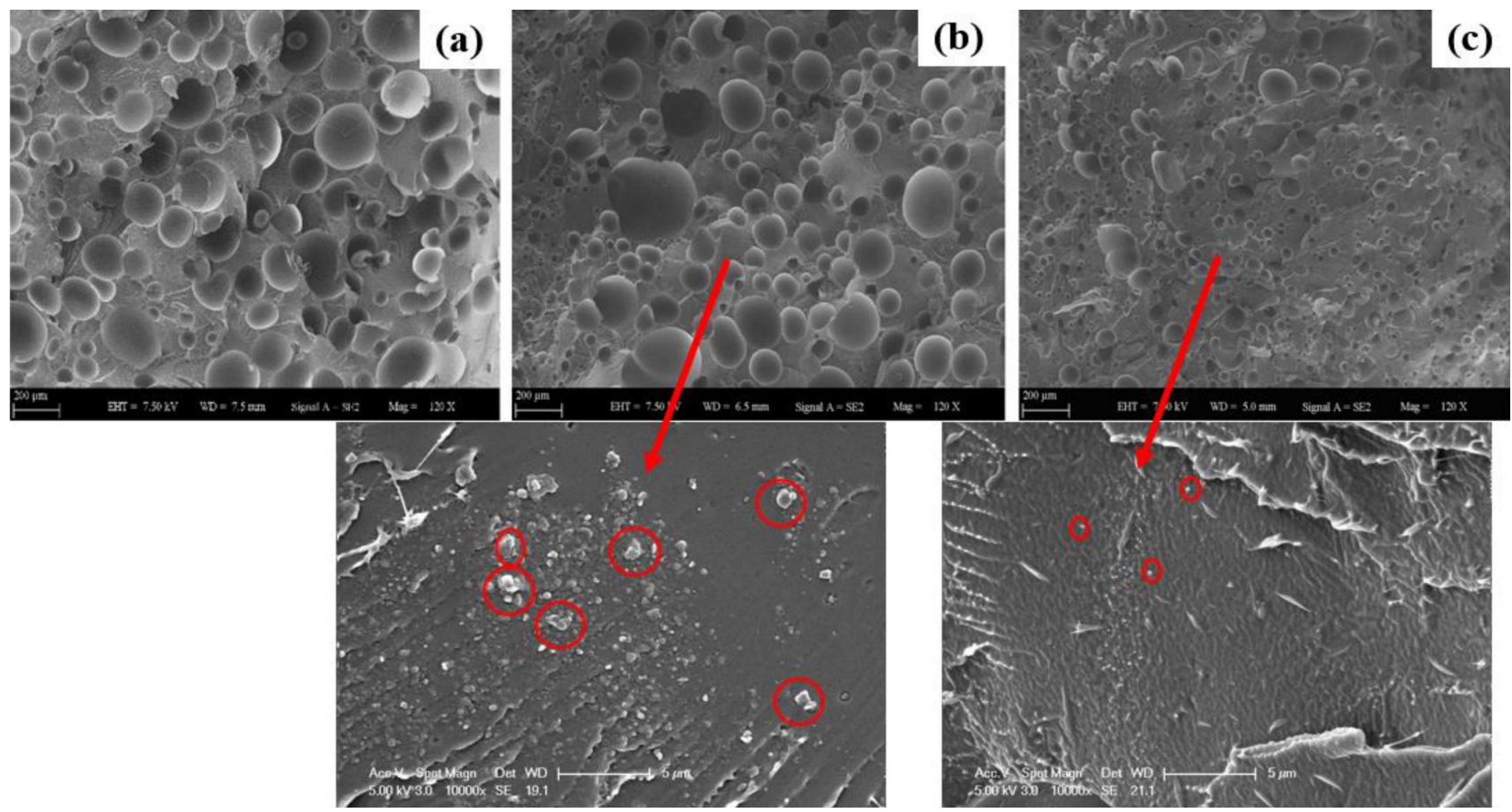

Fig. 1. SEM images of PLA foams: (a) neat PLA $150 \times$, (b) PLA/HNT $150 \times-10 \mathrm{k} \times$, (c) PLA $/ \mathrm{HNT} / \mathrm{AC} 150 \times-10 \mathrm{k} \times$.

foam (Fig. 1a). However, the pore size of the PLA foams decreased with the HNT addition (Fig. 1b, c). This indicated that the presence of halloysite nanotube in the matrix behaved as nucleating agent, promoting a fine distribution of cell nucleation, could enhance foaming homogeneity, mechanical, and physical properties $[4,11,12]$. Cell densities $\left(N_{\text {cell }}\right)$ were calculated using the following Eq. (1) where $n$ is the number of cells on the SEM image, $A$ is the area of the image, and $\rho_{p}$ and $\rho_{f}$ are the densities of the unfoamed and foamed sections of PLA, respectively [11, 12]. Area measurements of cells are performed using Image $\mathrm{J}$. The results are given in Table I. The cell size and cell density observations showed that $\mathrm{PLA} / \mathrm{HNT} / \mathrm{AC}$ gave $259.9 \%$ of higher cell density and $74.1 \%$ of smaller cell size than that of PLA/HNT samples. This is attributed to the presence of azodicarbonamide during melt-mixing stage that it enhanced the dispersion of the nanoparticles in the matrix by decreasing the viscosity of the polymer [3, 12-14]. The better dispersed nanofiller supported cell formation. Table I gives information about the weight reduction of the PLA foams. Higher weight reduction was obtained with $\mathrm{PLA} / \mathrm{HNT} / \mathrm{AC}$ foams due to the higher cell density as given in Table $\mathrm{I}$.

The stress-strain curves of the PLA, PLA-HNT and $\mathrm{PLA} / \mathrm{HNT} / \mathrm{AC}$ are given in Fig. 2. The enhanced ductility of PLA nanocomposite is clearly evident in Fig. 2. Processing of PLA composites with azodicarbonamide on the extruder provided better dispersion of the nanoparticles in the matrix. As a result, an increment in tensile strength was observed for PLA/HNT/AC although $\mathrm{PLA} / \mathrm{HNT}$ and $\mathrm{PLA} / \mathrm{HNT} / \mathrm{AC}$ had the same
Foamed sample results.

TABLE I

\begin{tabular}{l|c|c|c|c|c}
\hline \hline Material & $\begin{array}{c}\text { Weight } \\
{[\mathrm{g}]}\end{array}$ & $\begin{array}{c}\text { Weight } \\
\text { reduction } \\
{[\%]}\end{array}$ & $\begin{array}{c}\text { Cell } \\
\text { density } \\
{\left[\text { cell } / \mathrm{cm}^{3}\right]}\end{array}$ & $\begin{array}{c}\text { Average } \\
\text { cell size } \\
{[\mu \mathrm{m}]}\end{array}$ & $\begin{array}{c}\text { Skin } \\
\text { layer } \\
{[\mu \mathrm{m}]}\end{array}$ \\
\hline Solid PLA & 10.31 & - & - & - & - \\
PLA & 7.46 & 27.64 & $39.71 \times 10^{4}$ & $8.86 \times 10^{3}$ & 309.79 \\
PLA/HNT & 8.83 & 14.35 & $88.93 \times 10^{4}$ & $5.10 \times 10^{3}$ & 536.79 \\
PLA/HNT/AC & 7.34 & 28.80 & $320.00 \times 10^{4}$ & $1.32 \times 10^{3}$ & 427.65
\end{tabular}

concentrations of HNT. The reduction of mechanical strength in PLA/HNT was due to the possible agglomerations as shown in Fig. 1. The melt compounding without any coupling agent, dispersant, and foaming agent resulted in agglomerations and reduction of tensile properties.

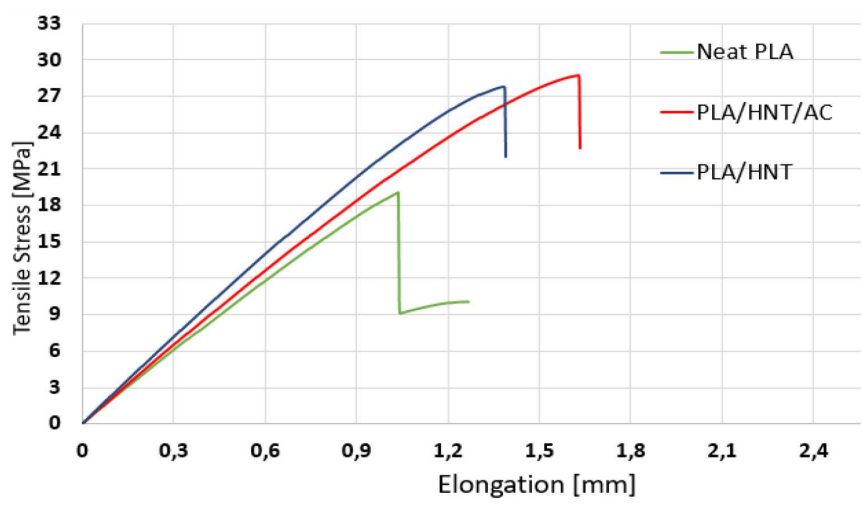

Fig. 2. Stress-strain curves of PLA foams. 


\section{Conclusion}

Mechanical strength and cell morphology of the PLA samples were improved by reinforcing PLA with halloysite nanotube. It has been seen that HNT addition in small amount could increase the tensile strength and elongation of the PLA foams about $50 \%$ and $77 \%$, respectively. Cell morphology of the PLA foams showed that HNT could improve the cell formation of the material. Also, the usage of azodicarbonamide in melt-mixing stage of PLA composites was considered as a plasticizer and it enhanced the nanoparticle dispersion in the matrix. As a result, better dispersion of HNT in the matrix provided improved cell morphology and a slight increment in tensile properties.

\section{Acknowledgments}

This work was supported by Research Fund of the Yildiz Technical University, Project Number: FDK-20183362 .

\section{References}

[1] A. Kramschuster, L.S. Turng, J. Biomed. Mater. Res. B Appl. Biomater. 92, 366 (2010).

[2] A. Ameli, M. Nofar, D. Jahani, G. Rizvi, C.B. Park, Chem. Eng. J. 262, 78 (2015).
[3] V. Peinado, L. García, Á. Fernández, P. Castell, Comp. Sci. Technol. 101, 17 (2014).

[4] R. Pantani, V. Volpe, G. Titomanlio, J. Mater. Process. Technol. 214, 3098 (2014).

[5] S. Pilla, A. Kramschuster, L. Yang, J. Lee, S. Gong, L.S. Turng, Mater. Sci. Eng. C 29, 1258 (2009).

[6] X. Liao, A.V. Nawaby, H.E. Naguib, J. Appl. Polym. Sci. 124, 585 (2012).

[7] Å. Larsen, C. Neldin, Polym. Eng. Sci. 53, 941 (2013).

[8] R. Pantani, A. Sorrentino, V. Volpe, G. Titomanlio, AIP Conf. Proc. 1593, 397 (2014).

[9] Y. Chen, L.M. Geever, J.A. Killion, J.G. Lyons, C.L. Higginbotham, D.M. Devine, Polym. Comp. 38, 2166 (2017).

[10] W. Wu, X. Cao, Y. Zhang, G. He, J. Appl. Polym. Sci. 130, 443 (2013).

[11] J. Wang, W. Zhu, H. Zhang, C.B. Park, Chem. Eng. Sci. 75, 390 (2012).

[12] N. Najafi, M.C. Heuzey, P.J. Carreau, D. Therriault, C.B. Park, Europ. Polym. J. 73, 455 (2015).

[13] N. Mantaranon, S. Chirachanchai, Polymer 96 54(2016)

[14] G. Wei, Z. Chun, Y. Jie, H. Ying, H. Li, Wuhan Univ. J. Nat. Sci. 19, 123 (2014). 